\title{
Crystallization after intravitreal ganciclovir injection
}

This article was published in the following Dove Press journal:

Clinical Ophthalmology

10 July 2010

Number of times this article has been viewed

Pitipol Choopong

Nattaporn Tesavibul

Nattawut Rodanant

Department of Ophthalmology, Siriraj Hospital, Mahidol University, Bangkok, Thailand
Correspondence: Pitipol Choopong Department of Ophthalmology, Siriraj Hospital, Mahidol University, 2 Prannok Road, Prannok, Bangkok Noi, Bangkok, Thailand 10200

Tel +66 24198033

Fax +6624111906

Email pitipol@hotmail.com
Purpose: To report crystal formation as a complication of intravitreal ganciclovir injection.

Patients and methods: A 73-year-old female patient with unilateral cytomegalovirus retinitis was treated with intravitreous ganciclovir ( $4 \mathrm{mg} / 0.04 \mathrm{~mL})$.

Results: After the intravitreal injection, sudden crystallization was observed in the vitreous humor. The patient experienced marked reduction in visual acuity and increased intraocular pressure. Despite aqueous paracenthesis and pars plana vitrectomy, optic atrophy was observed and her visual acuity remained unimproved after 12 months.

Conclusion: Crystal formation can occur as a complication of intravitreal ganciclovir injection. Associated retinal and optic nerve damage was found which results in permanent visual morbidity.

Keywords: ganciclovir, intravitreal injection, intraocular, CMV, toxicity

\section{Introduction}

Ganciclovir is an antiviral drug developed by Kelvin K Ogilvie in 1982 to use against herpesviruses. ${ }^{1}$ Dry ganciclovir powder should be completely reconstituted by sterile water before use. Systemic administration of ganciclovir is an effective therapeutic and preventative strategy for cytomegalovirus (CMV) retinitis. ${ }^{1-3}$ However, parenteral ganciclovir can cause serious toxicity including neutropenia, thrombocytopenia, anemia, phlebitis, and gastrointestinal disturbances. ${ }^{4}$ Therefore, local intraocular ganciclovir therapy had been introduced and widely used for patients who could not tolerate systemic treatment. ${ }^{5-7}$ The efficacy of local administration is comparable to systemic ganciclovir while the adverse effect is less. ${ }^{5-7}$ The known side effects of intravitreal injection are mostly related to the procedure rather than the drug itself including retinal detachment, vitreous hemorrhage, endophthalmitis, and cataract. ${ }^{5-7}$ Here, we first report a crystal formation as a rare unfavorable condition from intravitreal ganciclovir injection.

\section{Material and methods}

\section{Case report}

A 73-year-old Asian female patient presented with a history of chronic anterior uveitis and secondary increased intraocular pressure (IOP) in the right eye for 5 years. Her visual acuity was 6/24 and 6/9 in the right and left eye respectively. Intraocular pressures were 16 and $18 \mathrm{mmHg}$ in the right and left eye, respectively, with antiglaucoma drugs including timolol maleate $0.5 \%$ and brimonidine tartrate $0.15 \%$ eyedrops. 
Slit lamp biomicroscopic examination demonstrated $2+$ cells in the anterior chamber and an area of iris atrophy in her right eye. Fundoscopic examination showed inferotemporal retinal perivascular infiltration. Her complete blood count and chest X-ray were within normal limits. The purified protein derivative skin test, Veneral Disease Research Laboratory test, treponema pallidum hemagglutination test, and antiHIV were all negative. Topical steroid eyedrop and systemic immunosuppressive therapy (prednisolone acetate 1\% and methotrexate) were attempted without success.

A diagnostic aqueous paracenthesis was performed. Cytomegalovirus DNA was detected by polymerase chain reaction whereas herpes simplex and varicella zoster virus DNA was not found. A diagnosis of CMV retinitis was made. The options of systemic or local ganciclovir were considered. Because of the patient's advanced age and the unilateral involvement of the disease, local was chosen over systemic administration.

A therapeutic intravitreal injection of uniformly dissolved ganciclovir (4 mg/0.04 mL) was given to the right eye. Suddenly after the procedure, crystal formation was observed in the vitreous humor anterior to the optic disc (Figure 1). Concomitantly, the patient complained of sudden decreased vision and the IOP rose to $33 \mathrm{mmHg}$ in her right eye.

To treat the complication emergently, $0.1 \mathrm{~mL}$ of aqueous humor was immediately released resulting in the reduction of IOP to $14 \mathrm{mmHg}$. In addition, topical timolol maleate $0.5 \%$ and oral acetazolamide were administered. Despite the therapeutic procedures, the patient's visual acuity diminished to finger count at 1 foot. A fundoscopic examination showed retinal edema and cherry red spot in the macular region. A fundus fluorescein angiogram revealed delayed arm to

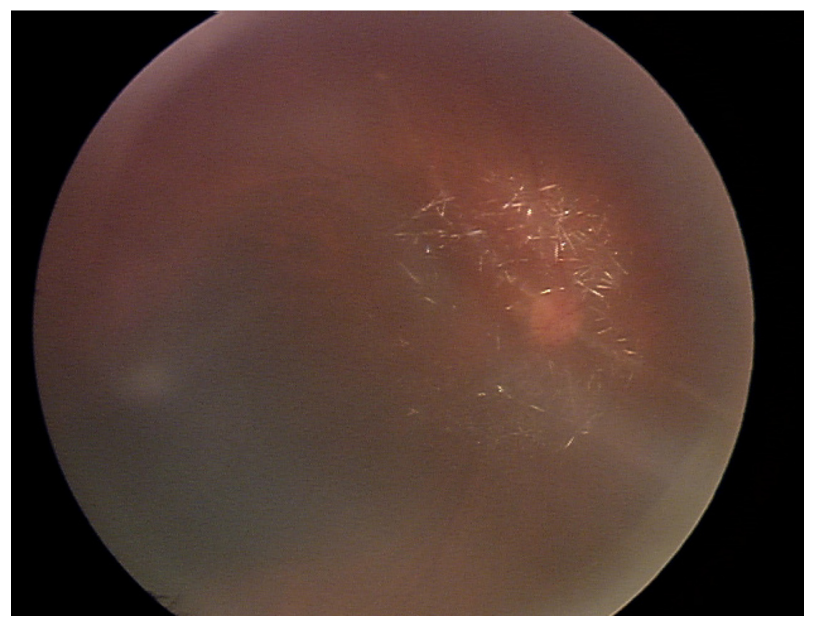

Figure I Fundoscopic photograph demonstrates crystallization of ganciclovir in the vitreous humor. retina time, cystoid macular edema, and late vascular leakage of the papillomacular bundle. A diagnosis of ganciclovir toxicity and associated central retinal artery occlusion was made. Pars plana vitrectomy was performed to remove the crystals along with intravitreal triamcinolone injection $(0.4$ $\mathrm{mg} / 0.1 \mathrm{~mL}$ ) to treat cystoid macular edema. Two weeks after the last procedure, the inflammation completely subsided, the IOP was well controlled, macula was flattened, but the optic disc became subsequently pale. Unfortunately, the patient's vision was not improved even after 12-month follow-up.

\section{Discussion}

Ganciclovir is an antiviral agent approved by United States Food and Drug Administration in 1989 to treat and prevent CMV retinitis. It is a synthetic nucleoside analog of guanine, which is active against human herpesvirus family including CMV. ${ }^{1,2}$ After intracellular phosphorylation, the active ganciclovir triphosphate inhibits replication of such viruses by interfering with the viral DNA synthesis.

Many routes of administration were reported for different uses. ${ }^{3}$ Parenteral ganciclovir is approved for induction and maintenance treatment of CMV retinitis in immunocompromised patients. ${ }^{3,4}$ Oral ganciclovir is recommended only in the maintenance phase after intravenous induction therapy or in prophylaxis treatment of solid organ transplant patients. Local treatment of CMV retinitis with intravitreal implant or intravitreal injection was introduced as an alternative to save cost and lower the risk of systemic side effects such as granulocytopenia and thrombocytopenia. Intravitreal injection demonstrated comparable efficacy to parenteral ganciclovir to control local progression of CMV retinitis in treated eye. ${ }^{5-7}$ The reported adverse effects included retinal detachment, vitreous hemorrhage, endophthalmitis, and cataract. In our unreported experiences, we used this high concentration of ganciclovir $(4 \mathrm{mg} / 0.04 \mathrm{~mL})$ to treat CMV retinitis because of two major reasons. First, due to a lot of CMV retinitis patients in our service, we decided to use alternate weekly injection $4 \mathrm{mg}$ of ganciclovir instead of $2 \mathrm{mg}$ of ganciclovir every week to reduce the number of patients in the clinic. While the risk of increased IOP is associated with volume of fluid injection, we decided to use lower volume as $0.04 \mathrm{~mL}$ to reduce that risk. With this method, less cases of increased IOP occurred.

In our case, the patient is immunocompetent with evidence of CMV-related retinitis in the right eye. After intravitreal ganciclovir was introduced, rapid crystallization in the vitreous humor concomitant with increase IOP occurred resulting in subsequent optic atrophy despite treatments. Although the 
reported dose of ganciclovir to treat $\mathrm{CMV}$ retinitis ranged from $400 \mathrm{mg}$ to $2 \mathrm{mg}$, our dose of $4 \mathrm{mg} / 0.04 \mathrm{~mL}$, verified to be effective to control CMV retinitis and low risk of retinal vascular occlusion by our unreported data, is about $2-10$ times doses normally used. We do speculate that such high drug concentrations introduced in the globe lead to sudden change of $\mathrm{pH}$ in the vitreous humor, might cause crystallization of ganciclovir. Nevertheless the exact reason of crystal forming is to be explored. Furthermore, this crystallization could cause ganciclovir overdosage in the vitreous humor and be toxic to the retina. Reviews of previous studies verified different concentration of intravitreal ganciclovir treatment with the maximum dose of $5 \mathrm{mg} / 0.1 \mathrm{~mL}$ injected..$^{5-7}$ They revealed no clinical signs of retinal or optic nerve toxicity. Nonetheless, in an experimental model done by Moschos et al, intravitreal ganciclovir injection of $200-600 \mathrm{mg} / 0.1 \mathrm{~mL}$ caused reduced to extinguish electroretinography with electron microscopic degeneration of photoreceptor cells and optic nerve fibers. ${ }^{8}$ Beside this, the sudden changes in osmolarity and $\mathrm{pH}$ may also take a role in causing retinal intoxication although they were not evaluated in our case. By our observation, we report the first case of crystal formation in the vitreous humor as an unexpected event after injection of ganciclovir. The cause of crystal formation is unknown. This phenomenon subsequently leads to permanent damage of the retinal and optic nerve. Subsequent adverse event as such retinal ischemia also prevent the chance of retinal recovery after removal of the crystal.

\section{Acknowledgment}

The authors acknowledge the assistance of Ponpan Matangkasombut, MD, in checking the grammar in this work.

\section{Disclosure}

The authors report no conflicts of interest in this work.

\section{References}

1. Morse GD, Shelton MJ, O'Donnell AM. Comparative pharmacokinetics of antiviral nucleoside analogues. Clin Pharmacokinet. 1993;24(2):101-123.

2. Smee DF, Martin JC, Verheyden JP, Matthews TR. Anti-herpesvirus activity of the acyclic nucleoside 9-(1,3-dihydroxy-2-propoxymethyl) guanine. Antimicrob Agents Chemother. 1983;23(5):676-682.

3. Holland GN, Buhles WC, Mastre B, Kaplan H. A controlled retrospective study of ganciclovir treatment for cytomegalovirus retinopathy: use of a standard system for assessment of disease outcome. UCLA CMV Retinopathy Study Group. Arch Ophthalmol. 1989;107(12):1759-1766.

4. Studies of Ocular Complications of AIDS Research Group in collaboration with the AIDS Clinical Trials Group. Mortality in patients with the acquired immunodeficiency syndrome treated with either foscarnet or ganciclovir for cytomegalovirus retinitis. $N$ Engl J Med. 1992;326(4):213-220.

5. Yutthitham K, Ruamviboonsuk P. The high-dose, alternate-week intravitreal ganciclovir injections for cytomegalovirus retinitis in acquired immune deficiency syndrome patients on highly active antiretroviral therapy. J Med Assoc Thai. 2005;88 Suppl 9:S63-S68.

6. Ausayakhun S, Yuvaves P, Ngamtiphakom S, Prasitsilp J. Treatment of cytomegalovirus retinitis in AIDS patients with intravitreal ganciclovir. J Med Assoc Thai. 2005;88 Suppl 9:S15-S20.

7. Arevalo JF, Garcia RA, Mendoza AJ. High-dose (5000-microg) intravitreal ganciclovir combined with highly active antiretroviral therapy for cytomegalovirus retinitis in HIV-infected patients in Venezuela. Eur $J$ Ophthalmol. 2005;15(5):610-618.

8. Moschos M, Vamvasakis M, Kontogeorgos G, Papantonis F, Panagakis E, Chatzis V. Intravitreal application of ganciclovir in rabbits: ERG and electron-microscopic findings. Ophthalmologica. 1996;210(4):215-222.
Clinical Ophthalmology

\section{Publish your work in this journal}

Clinical Ophthalmology is an international, peer-reviewed journal covering all subspecialties within ophthalmology. Key topics include: Optometry; Visual science; Pharmacology and drug therapy in eye diseases; Basic Sciences; Primary and Secondary eye care; Patient Safety and Quality of Care Improvements. This journal is indexed on

Submit your manuscript here: http://www.dovepress.com/clinical-ophthalmology-journal

\section{Dovepress}

PubMed Central and CAS, and is the official journal of The Society of Clinical Ophthalmology (SCO). The manuscript management system is completely online and includes a very quick and fair peer-review system, which is all easy to use. Visit http://www.dovepress.com/ testimonials.php to read real quotes from published authors. 